Pacific Journal of Mathematics

ON FINDING THE DISTRIBUTION FUNCTION FOR AN
ORTHOGONAL POLYNOMIAL SET 


\title{
ON FINDING THE DISTRIBUTION FUNCTION FOR AN ORTHOGONAL POLYNOMIAL SET
}

\author{
Wm. R. Allaway
}

Let $\left\{a_{n}\right\}_{n=0}^{\infty}$ and $\left\{b_{n}\right\}_{n=0}^{\infty \infty}$ be real sequences with $b_{n}>0$ and $\left\{b_{n}\right\}_{n=0}^{\infty}$ bounded. Let $\left\{P_{n}(x)\right\}_{n=0}^{\infty}$ be a sequence of polynomials satisfying the recurrence formula

$$
\left\{\begin{array}{l}
x P_{n}(x)=b_{n-1} P_{n-1}(x)+a_{n} P_{n}(x)+b_{n} P_{n+1}(x) \quad(n \geqq 0) \\
P_{-1}(x)=0 \quad P_{0}(x)=1 .
\end{array}\right.
$$

Then there is a substantially unique distribution function $\psi(t)$ with respect to which the $P_{n}(x)$ are orthogonal. That is,

$$
\int_{-\infty}^{\infty} P_{n}(x) P_{m}(x) d \psi(x)=K_{n} \delta_{n, m} \quad(n, m \geqq 0),
$$

where $K_{n} \neq 0$ and $\delta_{n, m}$ is the kronecker delta. This paper gives a method of constructing $\psi(x)$ for the case $\lim _{n \rightarrow \infty} b_{2 n}=0$, $\lim _{n \rightarrow \infty} b_{2 n+1}=b<\infty$, the set of limit points of $\left\{a_{n}\right\}_{n=1}^{\infty}$ equals $\{-\alpha, \alpha\}$ and $\lim _{n \rightarrow \infty}\left\{a_{2 n}+a_{2 n+1}\right\}=0$. The same method can be used in the case $\lim _{n \rightarrow \infty} b_{n}=0$ and the set of limit points of $\left\{a_{n}\right\}_{n=0}^{\infty}$ is bounded and finite in number.

This continues the investigation started by Dickinson, Pollak, and Wannier [3] in which they studied the distribution function under the assumption $a_{n}=0$ and $\Sigma b_{n}<\infty$. Goldberg [4] extended their results by considering the case $a_{n}=0$ and $\lim _{n \rightarrow \infty} b_{n}=0$. Finally, Maki [5] showed how to construct the distribution function when $\lim _{n \rightarrow \infty} b_{n}=0$ and the set of limit points of $\left\{a_{n}\right\}_{n=0}^{\infty}$ are bounded and finite in number. In all these cases their approach was to study the continued fraction

$$
K(z)=\frac{1}{\mid z-a_{0}}-\frac{b_{0}^{2}}{\mid z-a_{1}}-\frac{b_{1}^{2} \mid}{\mid z-a_{2}} \cdots,
$$

where $\left\{b_{n}\right\}_{n=0}^{\infty}$ and $\left\{a_{n}\right\}_{n=0}^{\infty}$ consist of the same numbers as given in (1.1).

Our approach is different from that of the above mentioned authors. If $S(\psi)$ denotes the spectrum of $\psi$, i.e., the set $\{\lambda \mid \psi(\lambda+\varepsilon)-\psi(\lambda-\varepsilon)>0$ for all $\varepsilon>0\}$, then, in our case, we will show from the properties of the sequences $\left\{a_{n}\right\}$ and $\left\{b_{n}\right\}$ how to find the derived set of $S(\psi)$ and that the $S(\psi)$ consists of a denumerable set of points.

To prove our results we make use of the following theorem due to M. Krein ([1], p. 230-231).

Theorem 1.1. The polynomial set defined by (1.1) is associated with a determined Hamburger moment problem with solution $\psi$, such that $S(\psi)$ is bounded and the set of limit points of $S(\psi)$ is contained 
in $\left\{\alpha_{1}, \alpha_{2}, \alpha_{3}, \cdots, \alpha_{p}\right\}$ ( $\alpha_{i}$ real) if and only if the numbers $\alpha_{i}$ and $b_{i}$ $(i=0,1,2 \cdots)$ form a bounded set and $\lim _{i, k \rightarrow \infty} g_{i, k}=0$ where $g_{i, j}$ is the element in the ith row and $j$ th column of the matrix

$$
\prod_{i=1}^{p}\left(A-\alpha_{i} I\right)
$$

where

$$
A=\left\|\begin{array}{cccc}
a_{0} & b_{0} & 0 & \cdots \\
b_{0} & a_{1} & b_{1} & \cdots \\
0 & b_{1} & a_{2} & \cdots \\
\cdot & \cdot & \cdots \\
\cdot & \cdot & \cdots \\
\cdot & \cdot & \cdots
\end{array}\right\|
$$

2. Our main results.

THEOREM 2.1. Let $\lim _{n \rightarrow \infty} b_{2 n}=0$ and $\lim _{n \rightarrow \infty} b_{2 n+1}=b<\infty$, where $b>0$. The set of limit points of $\left\{a_{n}\right\}_{n=0}^{\infty}$ is $\{-\alpha, \alpha\}$ and $\lim _{n \rightarrow \infty}\left\{a_{2 n-1}+\right.$ $\left.a_{2 n}\right\}=0$ if and only if the derived set of $S(\psi)$ equals

$$
\left\{-\left(\alpha^{2}+b^{2}\right)^{1 / 2},\left(\alpha^{2}+b^{2}\right)^{1 / 2}\right\} \text {. }
$$

Proof. By using the notation of Theorem 1.1, it is easy to show that the element in the $i$ th row and $j$ th column of the matrix $A^{2}-\left(\alpha^{2}+b^{2}\right) I$ is given by

$$
g_{n, n+j}= \begin{cases}0 & \text { if }|j|>2, \\ b_{n-1} b_{n} & \text { if } j=2, \\ b_{n-1}\left(a_{n-1}+a_{n}\right) & \text { if } j=1, \\ b_{n-2}^{2}+a_{n-1}^{2}+b_{n-1}^{2}-\alpha^{2}-b^{2} & \text { if } j=0, \\ b_{n-2}\left(a_{n-2}+a_{n-1}\right) & \text { if } j=-1, \\ b_{n-2} b_{n-3} & \text { if } j=-2 .\end{cases}
$$

Let $\left\{-\left\{\alpha^{2}+b^{2}\right)^{1 / 2},\left(\alpha^{2}+b^{2}\right)^{1 / 2}\right\}$ constitute the derived set of $S(\psi)$. Because $\left\{b_{n}\right\}_{n=0}^{\infty}$ is bounded, then the Hamburger moment problem associated with (1.1) is determined (see [7], p. 59). Thus by Theorem $1.1 \lim _{i, j \rightarrow \infty} g_{i, j}=0$. Therefore, $\lim _{n \rightarrow \infty}\left(a_{2 n-1}+a_{2 n}\right)=0$ and $\lim _{n \rightarrow \infty}\left(a_{n}^{2}-\alpha^{2}\right)=0$. But this implies that the set of limit points of $\left\{a_{n}\right\}_{n=0}^{\infty}$ is $\{-\alpha, \alpha\}$.

Conversely if the limit points of $\left\{a_{n}\right\}_{n=0}^{\infty}$ is $\{-\alpha, \alpha\}$ and

$$
\lim _{n \rightarrow \infty}\left(a_{2 n-1}+a_{2 n}\right)=0 \text {, }
$$

then $\lim _{i, j \rightarrow \infty} g_{i, j}=0$. Thus by Theorem 1.1 this implies that the 
derived set of $S\left(\psi^{\prime}\right)$ has $-\left(\alpha^{2}+b^{2}\right)^{1 / 2}$ and $\left(\alpha^{2}+b^{2}\right)^{1 / 2}$ as its only two points. This completes the proof of the theorem.

Let $k$ be a positive integer and $\left\{\alpha_{1}, \alpha_{2}, \cdots, \alpha_{k}\right\}$ be a set of real numbers. If $g_{i, j, k}$ is the element in the $i$ th row and $j$ th column of the matrix

$$
\prod_{i=1}^{k}\left(A-\alpha_{i} I\right)
$$

then it is easy to show by mathematical induction on $k$ that

$$
g_{n, n-i, k}= \begin{cases}h_{i, n, k} \prod_{l=1}^{j} b_{n-l-1} & \text { if } 1 \leqq i \leqq k, \\ s_{n, k} b_{n-1}^{2}+q_{n, k} b_{n-2}^{2}+\prod_{i=1}^{k}\left(a_{n-1}-\alpha_{i}\right) & \text { if } i=0, \\ r_{i, n, k} \prod_{i=0}^{-i-1} b_{n+l-1} & \text { if }-k \leqq i \leqq-1, \\ 0 & \text { if }|i|>k,\end{cases}
$$

where $\left\{h_{i, n, i}\right\},\left\{r_{i, n, k}\right\},\left\{s_{n, k}\right\}$, and $\left\{q_{n, k}\right\}$ are bounded sequences in $n$ for fixed $k$ and $i$.

By using Equation (2.1) and the same technique as that used in the proof of Theorem 2.1 we have

THEOREM 2.2. Let $\lim _{n \rightarrow \infty} b_{n}=0$ and $\left\{a_{n}\right\}_{n=0}^{\infty}$ be a bounded sequence. The derived set of $S(\psi)$ equals $\left\{\alpha_{1}, \alpha_{2}, \cdots, \alpha_{p}\right\}$ if and only if the set of limit points of $\left\{\alpha_{n}\right\}_{n=0}^{\infty}$ is $\left\{\alpha_{1}, \alpha_{2}, \cdots, \alpha_{p}\right\}$.

Proof. Let $L=\left\{\alpha_{1}, \alpha_{2}, \alpha_{3}, \cdots, \alpha_{p}\right\}$ be the set of limit points of $\left\{a_{n}\right\}_{n=0}^{\infty}$. From Equation (2.1) and Theorem 1.1 we have that $D$, the derived set of $S(\psi)$, is contained in $L$. Assume $D$ is a proper subset of $L$. That is, $D=\left\{\beta_{1}, \beta_{2}, \beta_{3}, \cdots, \beta_{k}\right\}$ where $k<p$. Thus, if $g_{i, j, k}$ is the element in the $i$ th row and $j$ th column of the matrix $\prod_{i=1}^{k}\left(A-\beta_{i} I\right)$, then by Theorem 1.1 and Equation (2.1)

$$
\lim _{n \rightarrow \infty} \prod_{i=1}^{k}\left(a_{n-1}-\beta_{i}\right)=0 \text {. }
$$

That is, $L$ is a proper subset of $D$. But this is a contradiction. Thus $D=L$.

The converse may be proved in a similar manner.

Maki [6] conjectured, that in the case $\lim _{n \rightarrow \infty} b_{n}=0$, the set of limit points of $S(\psi)$ equals the set of limit points of $\left\{a_{n}\right\}_{n=0}^{\infty}$. Theorem 2.2 shows that this conjecture is true for the case when $\left\{a_{n}\right\}_{n=0}^{\infty}$ is bounded and has a finite set of limit points. Chihara [2] has shown by using the theory of continued fractions that Maki's conjecture is true in general. 
3. Construction of the distribution function. Because the sequence $\left\{b_{n}\right\}_{n=1}^{\infty}$ is bounded we are dealing with the determined Hamburger moment problem, so the continued fraction given in Equation (1.2) converges uniformly on every closed half plane,

$$
\operatorname{Im}(z) \geqq s>0,
$$

to an analytic function $F(z)$ which is not a rational function. $F(z)$ has the form

$$
F(z)=\int_{-\infty}^{\infty}(z-t)^{-1} d \psi(t)
$$

where $z$ satisfies (3.1). The polynomial set $\left\{P_{n}(x)\right\}_{n=0}^{\infty}$ given in (1.1) is orthogonal on $(-\infty, \infty)$ with respect to the distribution $\psi(x)$.

Let us define,

$$
A(x)=\psi(x+0)-\psi(x-0) .
$$

Lemma 3.1. Let $T$ be a bounded countable set of real numbers such that the derived set of $T$ is $B=\left\{\beta_{1}, \beta_{2}, \cdots, \beta_{n}\right\}$. Also let

$$
\begin{aligned}
H & =T \backslash B \\
& =\left\{h_{i} \mid i=1,2,3, \cdots\right\} .
\end{aligned}
$$

(i) $S(\psi)=H \cup B A\left(h_{j}\right)=M_{j}(j=1,2,3, \cdots)$, and $A\left(\beta_{k}\right)=N_{k}$ $(k=1,2,3 \cdots n)$, if and only if

(ii) $M_{j}>0(j=1,2,3, \cdots), N_{k} \geqq 0(k=1,2,3, \cdots n)$,

$$
\sum_{j=1}^{\infty} M_{j}+\sum_{k=1}^{n} N_{k}<\infty
$$

and

$$
F(z)=\sum_{j=1}^{\infty}\left(z-h_{j}\right)^{-1} M_{j}+\sum_{k=1}^{n}\left(z-\beta_{k}\right)^{-1} N_{k} .
$$

Proof. It is easy to show that $S(\psi)$ is closed. From this and by the definition of the Lebesgue-Stieltjes Integral, (i) implies (ii). Also from the fact that $S(\psi)$ is closed and from the Stieltjes inversion formula, (ii) implies (i). This completes the proof of the lemma.

Let $\mathscr{C}$ represent the field of complex numbers.

THEOREM 3.1. Let $\lim _{n \rightarrow \infty} b_{2 n}=0$ and $\lim _{n \rightarrow \infty} b_{2 n+1}=b<\infty$, where $b>0$. Also let the set of limit points of $\left\{a_{n}\right\}_{n=0}^{\infty}$ be $\{-\alpha, \alpha\}$ and $\lim _{n \rightarrow \infty}\left\{a_{2 n-1}+a_{2 n}\right\}=0$.

(i) $K(z)$ as defined by Equation (1.2) is a meromorphic function in $\mathscr{C} \backslash\left\{-\left(\alpha^{2}+b^{2}\right)^{1 / 2},\left(\alpha^{2}+b^{2}\right)^{1 / 2}\right\}$ and it has a representation of the form 


$$
K(z)=\frac{A\left(-\left(\alpha^{2}+b^{2}\right)^{1 / 2}\right)}{z+\left(\alpha^{2}+b^{2}\right)^{1 / 2}}+\frac{A\left(\left(\alpha^{2}+b^{2}\right)^{1 / 2}\right)}{z-\left(\alpha^{2}+b^{2}\right)^{1 / 2}}+\sum_{i=0}^{\infty} \frac{A\left(t_{i}\right)}{z-t_{i}}
$$

where $A\left( \pm\left(\alpha^{2}+b^{2}\right)^{1 / 2}\right) \geqq 0$ and $A\left(t_{i}\right)>0$.

(ii) If $T=\left\{t_{i} \mid i=1,2,3 \cdots\right\}$, where $t_{i}$ is as given in Equation (3.4), then $S(\psi)=T \cup\left\{-\left(\alpha^{2}+b^{2}\right)^{1 / 2},\left(\alpha^{2}+b^{2}\right)^{1 / 2}\right\}$.

(iii) The limit points of $S(\psi)$ are $-\left(\alpha^{2}+b^{2}\right)^{1 / 2}$ and $\left(\alpha^{2}+b^{2}\right)^{1 / 2}$.

Proof. We know from Theorem 2.1 that $S(\psi)$ is countable and its derived set consists only of the points $-\left(\alpha^{2}+b^{2}\right)^{1 / 2}$ and $\left(\alpha^{2}+b^{2}\right)^{1 / 2}$. Thus by Lemma 3.1

$$
F(z)=\frac{A\left(-\left(\alpha^{2}+b^{2}\right)^{1 / 2}\right)}{z+\left(\alpha^{2}+b^{2}\right)^{1 / 2}}+\frac{\mathrm{A}\left(\left(\alpha^{2}+b^{2}\right)^{1 / 2}\right)}{z-\left(\alpha^{2}+b^{2}\right)^{1 / 2}}+\sum_{i=1}^{\infty} \frac{A\left(t_{i}\right)}{z-t_{i}}
$$

where $T \cup\left\{-\left(\alpha^{2}+b^{2}\right)^{1 / 2},\left(\alpha^{2}+b^{2}\right)^{1 / 2}\right\}=S(\psi)$. Because $\psi$ is monotonically non-decreasing and $-\left(\alpha^{2}+b^{2}\right)^{1 / 2},\left(\alpha^{2}+b^{2}\right)^{1 / 2}$ are the only limit points of its spectrum we obtain, $A\left(t_{i}\right)>0$ for $t_{i} \in T$ and

$$
A\left( \pm\left(\alpha^{2}+b^{2}\right)^{1 / 2}\right) \geqq 0 \text {. }
$$

But the continued fraction given in Equation 1.2 converges uniformly to $F(z)$ on any closed bounded set that doesn't contain $S(\psi)$. Thus $K(z)=F(z)$, for $z \notin S(\psi)$. This completes the proof of the theorem.

By working directly with $K(z)$ Maki ([5] Theorem (5.4)) proves that if $\lim _{n \rightarrow \infty} b_{n}=0$ and the set of limit points of $\left\{a_{n}\right\}_{n=0}^{\infty}$ is $\left\{\alpha_{1}, \alpha_{2} \cdots \alpha_{p}\right\}$ with $\left|\alpha_{i}\right|<\infty i=1,2 \cdots p$, then

(i) $K(z)$ is a meromorphic function in $\mathscr{C} \backslash\left\{\alpha_{1}, \alpha_{2}, \cdots, \alpha_{p}\right\}$ and has a representation of the form

$$
K(z)=\sum_{i=1}^{p}\left(z-\alpha_{i}\right)^{-1} A\left(\alpha_{i}\right)+\sum_{i=0}^{\infty}\left(z-t_{i}\right)^{-1} A\left(t_{i}\right),
$$

where $A\left(\alpha_{i}\right) \geqq 0$ and $A\left(t_{i}\right)>0$,

(ii) if $T=\left\{t_{i} \mid i=1,2,3 \cdots\right\}$ where $t_{i}$ is as given in Equation (3.5), then $S(\psi)=\left\{\alpha_{1}, \alpha_{2}, \cdots, \alpha_{p}\right\} \cup T$, and

(iii) the derived set of $S(\psi)$ is $\left\{\alpha_{1}, \alpha_{2}, \cdots, \alpha_{p}\right\}$.

By using Theorem 2.2 and a technique similar to the one used in our proof of Theorem 3.1 it is easy to see how to give a short proof of Maki's theorem.

\section{REFERENCES}

1. N. I. Ahiezer and M. Krein, Some questions in the theory of moments, Transl. Math. Monographs, Vol. 2, Amer. Math. Soc., 1962.

2. T. S. Chihara, The derived set of the spectrum of a distribution function, Pacific J. Math., 35 (1970), 571-574.

3. D. J. Dickinson, H. O. Pollak, and H. Wannier, On a class of polynomials orthogonal over a denumerable set, Pacific J. Math., 6 (1956), 239-247. 
4. J. L. Goldberg, Some polynomials orthogonal over a denumerable set, Pacific J. Math., 15 (1965), 1171-86.

5. D. P. Maki, On constructing distribution functions: A bounded denumerable spectrum with $n$ limit points, Pacific J. Math., 22 (1967), 431-452.

6. _ A note on recursively defined orthogonal polynomials, Pacific J. Math., 28 (1969), 611-613.

7. J. Shohat and J. Tamarkin, The problem of moments, Math. Surveys No. 1, Amer. Math. Soc., 1950.

Received August 16, 1972.

LAKEHEAD UNIVERSITY 


\section{PACIFIC JOURNAL OF MATHEMATICS}

\section{EDITORS}

RICHARD ARENS (Managing Editor)

University of California

Los Angeles, California 90024

\section{R. A. Beaumont}

University of Washington

Seattle, Washington 98105

\section{J. DuGundJI*}

Department of Mathematics

University of Southern California

Los Angeles, California 90007

D. Gilbarg and J. Milgram

Stanford University

Stanford, California 94305

ASSOCIATE EDITORS
E. F. BECKENBACH
B. H. NeumanN
F. WOLF
K. YoSHIDA

\section{SUPPORTING INSTITUTIONS}

UNIVERSITY OF BRITISH COLUMBIA

CALIFORNIA INSTITUTE OF TECHNOLOGY

UNIVERSITY OF CALIFORNIA

MONTANA STATE UNIVERSITY

UNIVERSITY OF NEVADA

NEW MEXICO STATE UNIVERSITY

OREGON STATE UNIVERSITY

UNIVERSITY OF OREGON

OSAKA UNIVERSITY

\author{
UNIVERSITY OF SOUTHERN CALIFORNIA \\ STANFORD UNIVERSITY \\ UNIVERSITY OF TOKYO \\ UNIVERSITY OF UTAH \\ WASHINGTON STATE UNIVERSITY \\ UNIVERSITY OF WASHINGTON \\ AMERICAN MATHEMATICAL SOCIETY \\ NAVAL WEAPONS CENTER
}

The Supporting Institutions listed above contribute to the cost of publication of this Journal, but they are not owners or publishers and have no responsibility for its content or policies.

Mathematical papers intended for publication in the Pacific Journal of Mathematics should be in typed form or offset-reproduced, (not dittoed), double spaced with large margins. Underline Greek letters in red, German in green, and script in blue. The first paragraph or two must be capable of being used separately as a synopsis of the entire paper. Items of the bibliography should not be cited there unless absolutely necessary, in which case they must be identified by author and Journal, rather than by item number. Manuscripts, in duplicate if possible, may be sent to any one of the four editors. Please classify according to the scheme of Math. Rev. Index to Vol. 39. All other communications to the editors should be addressed to the managing editor, or Elaine Barth, University of California, Los Angeles, California, 90024.

50 reprints are provided free for each article; additional copies may be obtained at cost in multiples of 50 .

The Pacific Journal of Mathematics is issued monthly as of January 1966. Regular subscription rate: $\$ 48.00$ a year (6 Vols., 12 issues). Special rate: $\$ 24.00$ a year to individual members of supporting institutions.

Subscriptions, orders for back numbers, and changes of address should be sent to Pacific Journal of Mathematics, 103 Highland Boulevard, Berkeley, California, 94708.

\section{PUBLISHED BY PACIFIC JOURNAL OF MATHEMATICS, A NON-PROFIT CORPORATION}

Printed at Kokusai Bunken Insatsusha (International Academic Printing Co., Ltd.), 270, 3-chome Totsuka-cho, Shinjuku-ku, Tokyo 160, Japan.

* C. R. DePrima California Institute of Technology, Pasadena, CA 91109, will replace J. Dugundji until August 1974.

Copyright (C) 1973 by

Pacific Journal of Mathematics

All Rights Reserved 


\section{Pacific Journal of Mathematics}

\section{Vol. 49, No. $2 \quad$ June, 1973}

Wm. R. Allaway, On finding the distribution function for an orthogonal polynomial

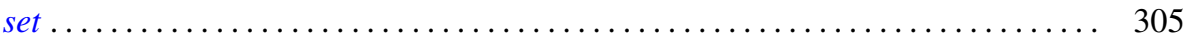

Eric Amar, Sur un théorème de Mooney relatif aux fonctions analytiques bornées... . 311

Robert Morgan Brooks, Analytic structure in the spectrum of a natural system . . . . 315

Bahattin Cengiz, On extremely regular function spaces . . . . . . . . . . . . . . 335

Kwang-nan Chow and Moses Glasner, Atoms on the Royden boundary . . . . . . . . . 339

Paul Frazier Duvall, Jr. and Jim Maxwell, Tame $Z^{2}$-actions on $E^{n} \ldots \ldots \ldots \ldots \ldots . .349$

Allen Roy Freedman, On the additivity theorem for $n$-dimensional asymptotic

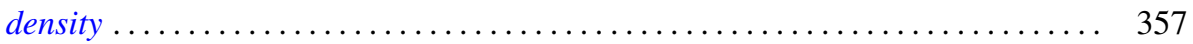

John Griffin and Kelly Denis McKennon, Multipliers and the group $L_{p}$-algebras . . . 365

Charles Lemuel Hagopian, Characterizations of $\lambda$ connected plane continua ....... 371

Jon Craig Helton, Bounds for products of interval functions . . . . . . . . . . . 377

Ikuko Kayashima, On relations between Nörlund and Riesz means . . . . . . . . . . 391

Everett Lee Lady, Slender rings and modules . . . . . . . . . . . . . . . . . . 397

Shozo Matsuura, On the Lu Qi-Keng conjecture and the Bergman representative

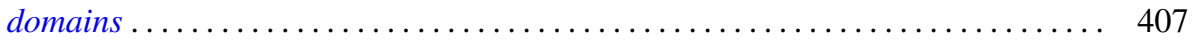

Stephen H. McCleary, The lattice-ordered group of automorphisms of an $\alpha$-set . . . 417

Stephen H. McCleary, o-2-transitive ordered permutation groups .......... 425

Stephen H. McCleary, o-primitive ordered permutation groups. II . . . . . . . . . 431

Richard Rochberg, Almost isometries of Banach spaces and moduli of planar

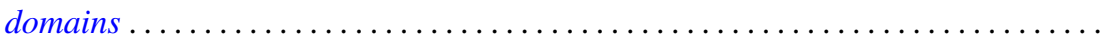

R. F. Rossa, Radical properties involving one-sided ideals . . . . . . . . . . . . . 467

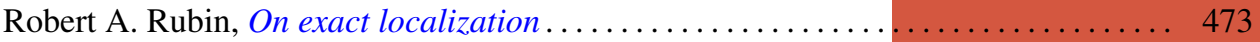

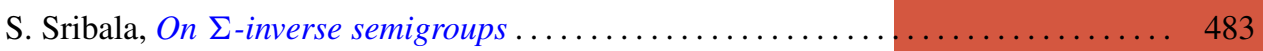

H. M. (Hari Mohan) Srivastava, On the Konhauser sets of biorthogonal polynomials suggested by the Laguerre polynomials ...................... 489

Stuart A. Steinberg, Rings of quotients of rings without nilpotent elements . ...... 493

Daniel Mullane Sunday, The self-equivalences of an $H$-space . . ............ 507

W. J. Thron and Richard Hawks Warren, On the lattice of proximities of $\check{C} e c h$

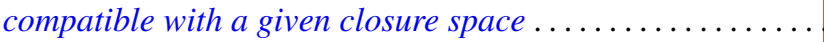

Frank Uhlig, The number of vectors jointly annihilated by two real quadratic forms determines the inertia of matrices in the associated pencil .

Frank Uhlig, On the maximal number of linearly independent real vectors annihilated simultaneously by two real quadratic forms ..............

Frank Uhlig, Definite and semidefinite matrices in a real symmetric matrix pencil . . 561

Arnold Lewis Villone, Self-adjoint extensions of symmetric differential operators . . . 569

Cary Webb, Tensor and direct products . ....................... 579

James Victor Whittaker, On normal subgroups of differentiable

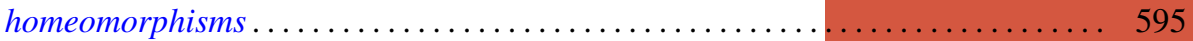

Jerome L. Paul, Addendum to: "Sequences of homeomorphisms which converge to

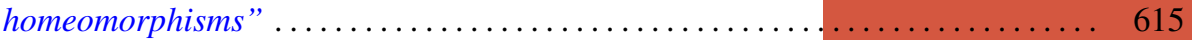

David E. Fields, Correction to: “Dimension theory in power series rings” ........ 616

Peter Michael Curran, Correction to: “Cohomology of finitely presented groups”. . . 617

Billy E. Rhoades, Correction to: “Commutants of some Hausdorff matrices” ...... 617

Charles W. Trigg, Corrections to: "Versum sequences in the binary system” ...... 619 